\title{
Jaakko Hämeen-Anttila, Khwadāynāmag: The Middle Persian Book of Kings, Brill, Leiden-Boston 2018, 282 pp., ISBN 978-90-043-6546-9
}

Das Khwadāynāmag ist eines der geheimnisvollsten Bücher der alten Welt und zählt zweifellos zu den schwerwiegendsten Verlusten antiker Literatur. In der Tat handelte es sich hierbei um den scheinbar ersten und einzigen Versuch, die Geschichte des vorislamischen Iran aus sasanidischer Perspektive wiederzugeben und somit zum erstenmal aus der Tradition mündlicher Überlieferung oder kurzer Inschriften auszubrechen, um auch literarisch ein umfassendes Narrativ festzuhalten, das zumindest ansatzweise mit dem der griechisch-römischen Literatur konkurrieren konnte, was allein schon ausreichen würde, es als unbestrittene Hauptquelle sasanidischer Selbstwahrnehmung anzusehen. Da aber das Werk, über dessen genauen Inhalt, Umfang und Form bis heute heftig gestritten wird, nahezu spurlos aus der direkten Überlieferung verschwunden ist, weil sowohl der mittelpersische Originaltext als auch sämtliche arabische Übersetzungen verlorengegangen sind, muß jeder Versuch einer Rekonstruktion aufgrund der erhaltenen, meist widersprüchlichen Testimonia und Fragmente zu einer überaus hypothetischen Angelegenheit werden. Handelte es sich um eine nahezu epische Zusammenstellung allen verfügbaren historischen und legendarischen Wissens, also um eine Art „Urtext“ Firdausis, dessen Shāhnāme letztlich nur eine leicht überarbeitete Fassung dieser Summa iranischer historischer Gelehrsamkeit darstellen würde? Oder im Gegenteil nur um eine kurze, trockene Aufzählung einiger Königsnamen mit ungefähren Regierungsdaten und verstreuten historischen Anmerkungen und anekdotischem Material? Die Frage ist bis heute seit Nöldekes bahnbrechenden Studien heißumstritten, und es ist ein großer Verdienst des Verfassers vorliegender Untersuchung, die langandauernde Diskussion nicht etwa spekulativ fortzusetzen, sondern zum Ursprung zurückzugehen und systematisch die Belege zur genauen Natur und Überlieferung des Khwadāynāmag zu sichten und, auf Grundlage der bisherigen Forschung, von Grund auf neu zu bewerten.

Dies erklärt dann auch den Aufbau des Werkes. In einem ersten Kapitel, „The Khwadāynāmag and Its Context" (S. 1-25), bemüht Hämeen-Anttila sich um eine strenge terminologische Unterscheidung verschiedener, oft unbedarft und inflationär benutzter Ideen und Begriffe bezüglich der Rekonstruktion des Khwadāynāmag und seiner Rezeption und reflektiert über das sonstige zeitgenössische Vergleichsmaterial iranischen und griechisch-römischen Ursprungs. Das folgende Kapitel, „Transmitting Materials over a Linguistic Border" (S. 26-58), gibt eine kurze Einführung zu jenem Übersetzungsschub, mit dem mittelpersische Texte im ersten Jahrtausend in andere Sprachen, allen voran das Arabische, übertragen wurden, wobei der Alexanderroman natürlich eine herausragende Rolle spielte. „Arabic Translations of the Khwadāynāmag“" (S. 59-130) 
bezeichnet dann den Titel des ersten eigentlichen Hauptteils des Buches, in welchem Hämeen-Anttila systematisch jede einzelne arabische Übersetzung bzw. textnahe Verarbeitung des verlorenen sasanidischen Werkes vorstellt und diskutiert: ein in Anbetracht der Tatsache, daß auch jene Übersetzungen verschollen und nur durch Fragmente und Testimonien bekannt sind, überaus heikles Unterfangen, das der Verf. aber in der ihm eigenen, äußerst bedachten und vorsichtigen Weise in Angriff nimmt. Besonders bedeutsam sind hier naturgemäß die Ausführungen zu Mūsā ibn 'Īsā al-Kisrawī (S. 76-89) und zu Ibn al-Muqaffa ${ }^{\circ}$ und seiner Nihāyat al-arab (S. 89-99). Der zweite Hauptteil des Buches ist dem Fortleben des verschollenen Khwadāynāmag in der islamisch-iranischen Literatur gewidmet und diskutiert dementsprechend die „Classical Persian Shāhnāmes“ (S. 131-173); jene halbbiographische, um Leben und Taten iranischer Könige angeordnete Literaturgattung, welche vor allem im Prosa-Shāhnāme (S. 141-147) sowie in Firdausis Epos (S. 152-167) ihren wichtigsten Niederschlag gefunden hat, und deren Bezug zum Khwadāynāmag als (angeblicher) Hauptquelle bis heute überaus strittig ist. Nach „Two Case Studies“ (S. 184-212), welche der Entwicklung der Sagen um Rustam (S. 174-199) sowie Armāȳ̄l und Garmāȳ̄l (S. 199-212) in der arabischen und persischen Literatur gewidmet sind, bietet „Back to the Khwadāynāmag“ (S. 213-232) die Quintessenz der im Laufe der Studie gewonnenen Resultate. Besonders hilfreich für den Nutzer dürfte die Zusammenstellung der wichtigsten Testimonia in „Translations of the Key Texts Concerning the Khwadāynāmag“ (S. 233-249) sein, ebenso wie die umfassende Bibliographie (249-270, in der leider allerdings die nützlichen Überlegungen zum Khwadāynāmag in dem von Chr. Jullien herausgegebenen Sammelband Husraw Ier, reconstruction d'un règne, Paris, 2015, fehlen), die zusammen mit den üblichen Indices (S. 271-282) das Werk abschließt.

Die Resultate der Studie sind, kurzgefaßt, folgende: Hämeen-Anttila geht, im Gegensatz zu früheren Hypothesen, nicht von der Existenz mehrerer Fassungen des Khwadāynāmag oder gar einer umfassenden, sich in unterschiedlichen Texten widerspiegelnden Khwadāynāmag-Tradition aus, sondern nur von einem einzigen Werk, was natürlich nicht ausschließt, daß spätere sasanidische oder islamische Schreiber möglicherweise die Daten und Taten derjenigen Großkönige ergänzten, die nach der Regierungszeit des Herrschers amtierten, der für die ursprüngliche Niederschrift des Khwadāynāmag verantwortlich war, ohne daß diese Vervollständigungen dazu berechtigen würden, von mehreren „konkurrierenden“ Fassungen zu sprechen (ebensowenig wie mögliche Kürzungen, Glossen bzw. Übertragungsfehler der arabischen Übersetzer). Auch, was Inhalt, Umfang, Quellen und Entstehungszeit des Khwadāynāmag betrifft, vertritt Hämeen-Anttila eine überaus vorsichtige, geradezu minimalistische Position, wie sich auch sein gesamtes, wohlerwogenes Buch als Versuch deuten läßt, einen Minimalkonsens zu erstellen, auf dessen Boden dann möglicherweise andere, spekulativere Hypothesen errichtet werden könnten. So vermutet der Verf., daß das Buch wohl in Länge und Ausschmückung kaum, wie manchmal angenommen, mit Firdausis Shāhnāme zu vergleichen gewesen sein muß (auch wenn dieser, durch Vermittlung des ProsaShāhnāme, zumindest teilweise aus dem Material des Khwadāynāmag geschöpft hat), sondern wenig mehr als eine Aufzählung der Namen und Regierungszeiten vorislamischer iranischer Könige dargestellt hat, kombiniert mit einigen wichtigen Amtshandlungen, militärischen Siegen, Städtegründungen, Apophthegmata, Rundbriefen und 
Thronreden, insgesamt wohl etwa 10-30 Seiten lang. Zeitlich wird der Text, wie der Verf. annimmt, nur die sasanidische Zeit umfaßt haben, nicht aber, oder doch nur sehr lakonisch, die heroische und achaimenidische Zeit (letztere war ohnehin weitgehend in Vergessenheit geraten); und selbst Alexander, die Seleukiden und die Parther werden nur höchst summarisch erwähnt worden sein. Angesichts der Möglichkeit einer sukzessiven Vervollständigung des Werks durch spätere Generationen ist es naturgemäß schwer, die genaue Entstehungszeit auszumachen. Die in der Literatur meist kritiklos übernommene Datierung des Khwadāynāmag entweder in die Regierungszeit Chosraus I. bzw. Chosraus II. basiert jedenfalls, wie Hämeen-Anttila überzeugend nachweist, nur auf oft fragwürdigen Evidenzen, keineswegs Beweisen, wobei allerdings auch der Verf. letztlich diese beiden Könige als die wahrscheinlichsten, aber eben nicht sicheren Auftraggeber des Werkes annimmt.

Insgesamt läßt sich festhalten, daß es sich bei vorliegender Arbeit um eine gut geschriebene, sorgfältig durchdachte, ebenso vorsichtige wie überzeugende Studie handelt, die freilich die eine oder andere liebgewonnene und in vielen Handbüchern tradierte Lehrmeinung als fragwürdige Hypothese bloßstellt, gerade darum aber von der Forschung als Ausgangspunkt aller künftigen Überlegungen zum Khwadāynāmag genommen werden muß.

David Engels (Université libre de Bruxelles / Instytut Zachodni, Poznań) 